(1) Jurnal Thariqah IImiah Vol. 07 No. 02 Desember 2019

الإنشاء الطلبي في سورة التحريم (دراسة بلاغية)

إعداد

\title{
سيتي عرفة
}

الإنشاء في البلاغة هوكلام لا يحتمل على صدق وكذب. ينقسم الإنشاء إلى طلبي وغير

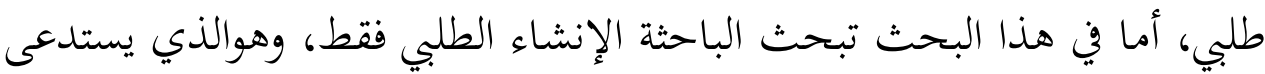
مطلوبا غير حاصل في إعتقاد المتكلم وقت الطلبي. ويكون بخمسة أشياء : الأمر والنهي والإستفهام والتمني والنداء. و أما أسئلة البحث في هذا البحثنوهي : ( ) ما هي أقسام الإنشاء الطبي الموجودة في سورة التحريع؟ . r) ما هي معاني الإنشاء الطلبي الموجودة في سورة التحريك؟. واستخدمت الباحثة في هذا البحث بطريقةتحليلية البلاغية لتجد الإنشاء الطبي ومعناه في سورة التحريم. وله مصدرين، البيانات الأساسية والإضافية. أما الأساسية فهوالقرآن الكريم،والإضافية فهوالكتب التي متعلقة ههذا الموضوعمن كتب التفسير والبلاغة-والقاموس. بعد ما بحثت الباحثة فوجدت في سورة التحريم ـ ب كلمة بالإنشاء الطلبي. وهي عشر كلمات لأمر، كلمة واحدة للنهي، كلمتين لإستفهام، كلمتين للتمني، وخمس كلمات للنداء. وأما معاني الإنشاء الطبي في سورة التحريم هناك معنى الحقيقي

وغير الحقيقي. كل معاني الأمرفي سورة التحريم بغير حقيقي هي:النصح-الإرشادالدعاء-التأديب-الإهانة. ومعانى النهي بغير حقيقي أيضا هي : والتوبيخ. معناني الإستفهام هنا كالحقيقي وهي : (قالت من أنبأك هذا) وهناك معنى غير حقيقي هي: الإنكار. ومعاني التمني هي معنى الترجي. ومعاني النداء كل معنده بغير الحقيقي هي : المدح والذم.

الكلمة المفتوحة: الإنشاء الطلبي في العربية : معاني الإنشاء الطلبي في سورة التحريم 


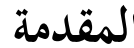

أن القرآن أعظم معجزات النبي صلى الله عليه وسلم حجة على نبوته

وبرهانا على صدقرسالته، وكان القرآن مصدر الدين ومنبع من منباع العلوم ومعارف في الأرض.فالا غرومن ان يأتي القرآن وافيابجميع المطالب الحياة الإنسانية على الأسس

للأديانالسماوية..وتحدي رسول الله صلى اللهعليه وسلم العرب بالقرآن، وقد نزل بلساهم، وهم أرباب الفصاحة والبيان، فعجزو ان يأتي بمثله أوبعشر سور مثله، أوبسورة من مثله، فثبت له الإعجاز، وبإعجازه ثبتت الرسالة. ' فللقرآن تعاريف كثيرة بين المفسرين ومن الكتب المختلفة، منها: القرآن في اللغة هوالمصدر من فعل (قرأ).يقال : قرأ-يقرأ-قرءا-قراءة-قرآنا. بثم نقل من هذا المعنى المصدرى، وجعل إسما للكالام المعجز المنزل على النبي صلى الله عليه وسلم، من باب المصدر على مفعوله. فالقرآن على هذا يكون بمعنى المقروء. مَّينزل القرآن بالعربية.واللغة العربية هي الكلمات التي تعبر بها العرب عن أغراضهم، وقد وصلت إلينا من طريق النقل. وحفظها لنا القرآن الكريم والأحاديث الشريفة. وُجعل الله لغة العربية لغة لإتحاد مسلم في العالم والخناص في بلاد المسلمين.

واللغة العربية أيضا وسيلة يتعقل بها معاني القرآن كما قال الله تعإلى

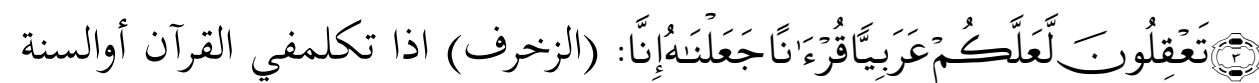
بدون معرفة هذه الوسيلة كان متكلما برأيه لا علم كذلك يأخذ حكما شرعيا من Halim Surabaya, Sa’ban 1418 H-:Sumenab ('Akhmad Sya’bi, Kamus Al-Qalam, , hal. 198)Desember 1997 M

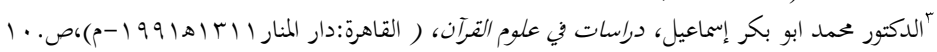


حيث لا يدري أهوثابت أم باطل. ُوماكان القرآن كلاما عربيا كانت قواعد العربية طريقا لفهم معانيه، وبدون ذلك يقع الغلط وسواء الفهم لمن ليس بعربي بالسليقة، ونعني بقواعد العربية : بحموع اللسان العربي، وهومتن اللغة، والتصريف، والنحو، والغريب، والإعراب، والمعاني، والبيان، والبديع. '

من إحدى معجزات القرآن في لغته : الأدبي، البلاغة، الفصاحة، الأسلوب، وشكل جمله. لغة العربية له جميلة وأسلوب الذي لا يملك لغة الأخرى. كما قال الله تعإلى:

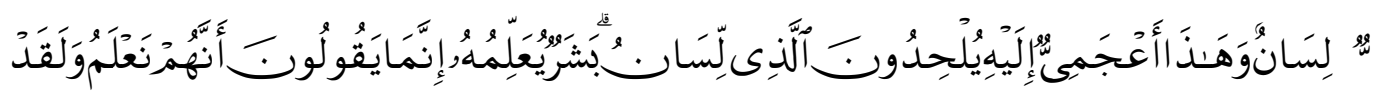

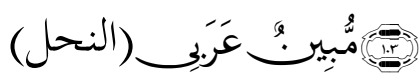

وكان القرآن الكريم لا تنقضي معجزاته ولا عجائبه في لغته وأسلوبه وفي وقعه

الصوتي وجماله اللغوي في لحن وغريب، وتوقيع عجائبه يفوق حسنه وجماله كل ما عرف من توقيع الموسيقى، وترنيم الشعر، وواسعه في اللغة مقالا. لِوالعلوم العربية هي العلوم التي يتوصل بها إلى عصمة اللسان والقلم عن الخطاء، وهي ثلاثة عشر علما : الصرف، والإعراب (ويجمعهما النحو)، وارسم، والمعاني، والبيان، والبديع، والعروض،

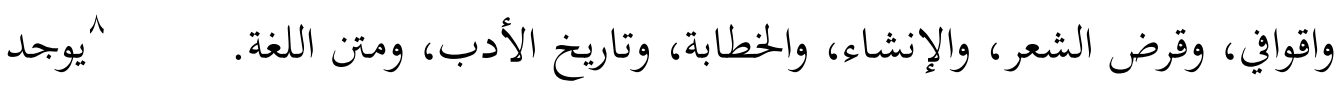
خمسةمن مفهوم الإنشاء الطلبي من كتب مختلفة بينها: الإنشاء الطلبي هوالذي

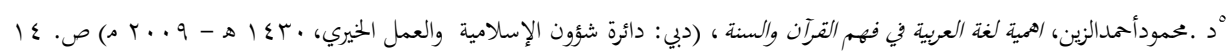

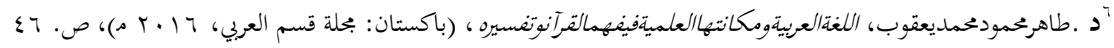
http://diglib.uinsby.ac.id./id/eprint/12001

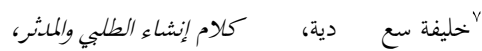
resisundergradutepdf).

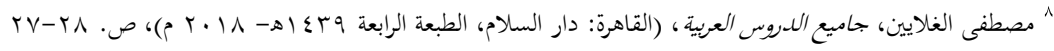


يستدعي مطلوبا غير حاصل في إعتقاد المتكلم وقت الطلبي- ويكون بخمسة أشياء:الأمر والنهي والإستفهام والتمني والنداء.

وأما الإنشاء الطلبي فهوما يطلب حصول شيء لم يكن موجودا عند الطلبي وهوالأمر والنهي والإستفهام والرجاء والتمني والنداء. 'والإنشاء الطلبي هوما يستدعى مطلوبا غير حاصل وقت الطلبي. ويكون خاصة في: الأمر، النهي، الإستفهام، التمني، النداء.

فالإنساء الط لبي هوما يستدعى مطلوبا غير حاصل في وقت الطلبي. وهوخمسة أنواع على وجه التالي: الأمر والنهي والإستفهام والتمني والنداء. هذه هي إنشاءالطبي خمسة، وكل واحد منها لا يحتمل صدقا ولا كذبا، وإنما يطلب به حصول به شيء لم يكن حاصلا وقت الطلبي، ولذلك يسمى فيها الإنشاء طلبيا. والمقصود هنا الطلبي وهوما يستدعى مطلوبا غير حاصل وقت الطلبي لإمتناع طلب الحاصل الشيء على سبيل المحبة واللفظ الموضوع له (ليت) ولا يشترط إمكان التمني بخلاف المرتجي نهو(ليت الشباب عائدا) كذا قالوه.

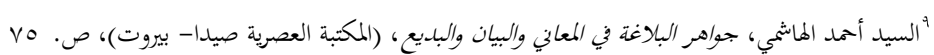

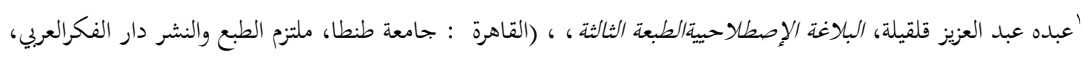

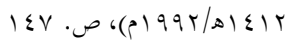

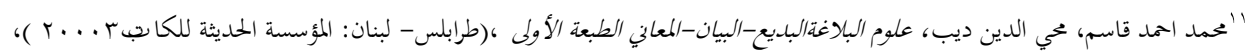
rAr.

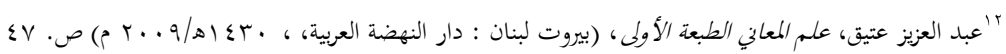
"' جلال الدين السيوطي،شرح عقود الجمان في المعاني والبيان ، -(بيروت ، لبنان : دار الكتب العلمية ، 11 • ب)، ص. ابسا
} 
وأما سورة التحريم مدنية في قول الجميع، فهي إثنتا عشرة أية. وتسمى سورة (النبي).' ويقال لها: سورة المتحرم، وسورة لم تحرم، وسورة النبي، وعن ابن الزبير : سورة النساء. والمشهور أهما مدنية،وعن قتادة أن المدني منها إلى رأس العشر والباقي مكي، وآياةما إنتتا عشرة آية بإتفاق، وهي متوخية مع التي قبلها في الإفتتاح بخطاب النبي صلى الله عليه وسلم، وتلك مشتملة على طلاق النساء، وهذه على تحريم الإماء، وبينهما من الملابسة مالا يخفى، وملاكانت تلك في خصام نساء الأمة ذكر في هذه خصومة نساء المصطفى صلى الله عليه وسلم إعظاما لمنصبهن أن يذكرن مع سائر النسوة فأفردن بسورة خاصة، ولذا ختمت بذكر زوجية صلى الله عليه وسلم في الجنة آسيى امرأة فرعون، ومريم بنت عمران، قاله الجحلال السيوطي عليه الرحمة. ْوأما قال عبد الرزاق : قال معمر : وأما قتادة فقال حرمها فكانت يمينا.معمر عن هشام بن عروة عن أبيه قال: كان النبي صلى الله علية وسلم إذا صلى الصبح دخل على امرأته فسلم عليهن، وكانت حفصة قد أهتدى لها عسل، وكان النبي إذا دخل عليها خاضت له من ذلك العسل فسقته منه فيجلس عندها، فغارت عائشة فجمعتهن فقالت لأزواج النبي صلى الله عليه وسلم امرأة : إذا دخل عليكن فقولي: ما هذا الريح التي أجدها منك يا رسول الله؟ أكلت مغافر؟ فإنه سيقول: سقتني حفصة عسلا فقولي: جرست نحلة العرفط، قال: فدخل على سودة، قالت: فأردت أن أقول له قبل ان يدخل فرقا من عائشة، قالت: فلما دخل قالت: ما هذا الريح التي أجد منك يا رسول الله؟ أكلت مغافير؟ قال : لا،ولكن حفصة سقتني عسلا، فقالت: جرست نحله العرفط، ثم دخل عليهن امرة امرة وهن يقلن له ذلك ثم دخل على

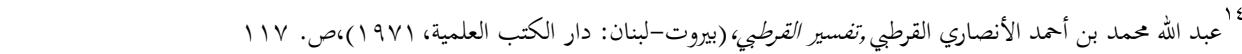

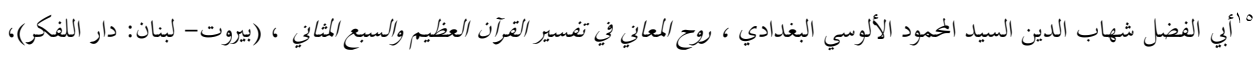


(6) Jurnal Thariqah IImiah Vol. 07 No. 02 Desember 2019

عائشة فقالت له ايضا ذلك، فلما كان الغد دخل على حفصة فسقته فأبى أن يشرب وحرمه عليه، فأنزل الله تعإلى :(التحريم). 17

وبعد ما شرحت الباحثة عن مفهوم الإنشاء الطلبي وأقسامه، ولمحة عن سورة التحريم، فأخذت الباحثة تحليل أقسام الإنشاء الطلبي ومعانيها الموجودة في سورة التحريم.

قسمت الباحثة هذا الكث إلى قسمين، القسم الأول أقسام الإنشاء الطلبي

الموجودة في سورة التحريم. والقسم الثاني معاني الإنشاء الطلبي الموجودة في السورة التحريم. وينقسم هذا التحليل إلى خمسة أنواع، إعتمادا على أقسام الإنشاء الطلبي التي كتبتالباحثة في الباب الثاني من هذا البحث العلمي، هو: الأمر، النهي، الإستفهام، التمني، النداء.

أقسام الإنشاء الطلبي الموجودة في سورة التحريم :

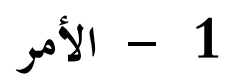

قسم الأول من الإنشاء الطلبي الموجودة في سورة التحريم يعني في آية 6، 8، 9،

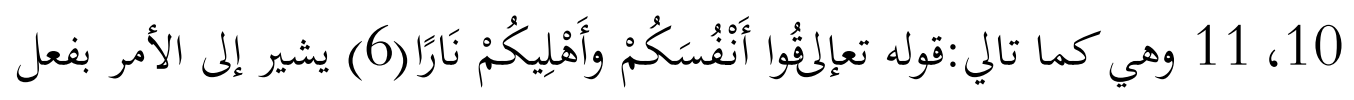
الأمر الصريح. و "قوا" فعل الأمر من الوقاية فوزنه "عوا" لأن الفاء (فاء الفعل) حذفت لوقوعها في المضارع بين ياء وكسرة أي "يوقي"واللام (لام الفعل) محذوف على البخزومفتكون "ق" لكن لأان في هذه الأية الكريمة يشير على الجمع فتكون "قوا". ومن المعروف في الأسلوب القرآي اتخاذ الحادثة الجزئية سبيلا إلى التعميم وسوق الهديات

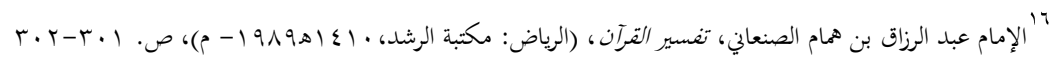


الشاملة إلى الإنسانية،فمن حادثة المتظاهرتين إلى مخاطبة المؤمنين إلى مخاطبة الكافرين

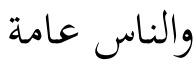

وقوله تعإلى :تُوبُوا إلى اللَّهِ تَوبَةَ نَصُوحًا (8) يشير إلى الأمر بفعل الأمر الصريح، من كلمة "تاب-ـيتوب-تب. لكن بإلتقاء الساكنين وهوفي حرف علة ولام الفعل فحذفت حرف العلة فتكون "تب" ولكن لأن في هذه الآية الكريمة يشير إلى الجمع فتكون "توبوا" ولابد يظهر حرف العلة اذا لام الفعل ليس بالسكون. فصيغة الأمر عند الإطلاق تقتضي وجوب المأمور به والمبادرة بفعله فورا، كما وردت في الآية الكريمة.

وقوله تعإلى :رَبَّنَا أَتْمِمْ لَنَا نُورَنَا (8)يشير إلى الأمر بفعل الأمر الصريح،من كلمة "اتم-يتم-اتمم". فالأمر في هذه الآية يدل على سبيل الذلة والمسكنة والتواضع، لكون الآمر أعلى من المأمور وقد سمي دعاء.

وقوله تعإِلى:واغْفِرْ لَنَا (8) يشير إلى الأمر بفعل الأمر الصريح،من كلمة "غفر يغفر - اغفر". فالأمر في هذه الآية يدل على سبيل الذلة والمسكنة والتواضع، لكون الآمر أعلى من المأمور وقد سمي دعاءا.

وقوله تعإِلى:جَاهِدِ الْكُفَّارَ والْمْنَافِقِينَ(9) يشير إلى الأمر بفعل الأمر الصريح، من كلمة"جاهد-يجاهد-جاهد". خص النبي صلى الله عليه وسلم بالأمر بالجهاد،مع أن الأمر به يشمل المؤمنين معه، لأنه صلى الله عليه وسلم هوقائدهم ورائدهم، اي جاهد انت ومن معك من المؤمنين. 
وقوله تعإلى :واغْلُظْ عَلَّهِهْ (9)يشير إلى الأمر بفعل الأمر الصريح، من كلمة

"اغلظ-يغلظ-اغلظ". وهوالأمر بشداد على المنافقين في إقامة الحدود، لأن أكثر من يصيب الحد في ذلك المنافقون.

وقوله تعإِلى: ادْخُلا النَّارَ مَعَ الدَّاخِلِينَ (10) يشير إلى الأمربفعل الأمر الصريح، من كلمة دخل-يدخل -ادخل". وهذا الأمر لتثنية مؤنث غائب وهي إلى إمراة نبي نوح ونبي لوط.

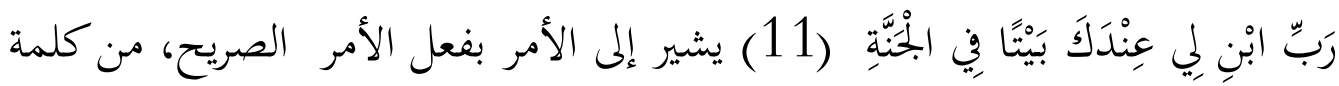
"بنى-يبني-ابن". فالأمر في هذه الآية يدل على سبيل الذلة والمسكنة والتواضع، لكون الآمر أعلى من المأمور وقد سمي دعاءا

وقوله تعإلى :وبَتِّيِ مِنْ فِرْعَونَ وعَمَلِهِ (11) يشير إلى الأمر بفعل أمر الصريح، من كلمة "بنى-ينجي-نج". فالأمر في هذه الآية يدل على سبيل الذلة والمسكنة والتواضع، لكون الآمر أعلى من المأمور وقد سمي دعاء.

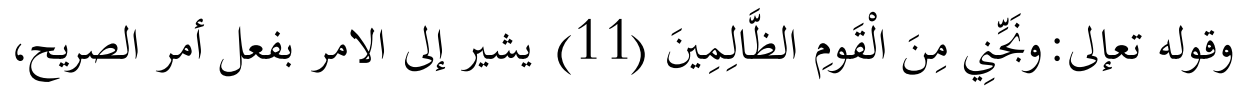
من كلمة "بنى-ينجي-نج".فالأمر في هذه الآية يدل على سبيل الذلة والمسكنة والتواضع، لكون الآمر أعلى من المأمور وقد سمي دعاء.

وإذا نظرت الباحثة إلى الآيات السابقة فوجدت ان كلمة : قوا-توبوا-اتمماغفر -جاهد-اغلظ-ادخلا-ابن-نجني، وكلها عشر كلمات توجد في خمس آيات، 
(9) Jurnal Thariqah Ilmiah Vol. 07 No. 02 Desember 2019

وكلها تدلعلى الأمر بصيغة واحدة فقط وهي صيغة فعل الأمر، ولم بجد الباحثة صيغة أخرى مثل :صية الأمر بفعل المضارع الذي يدخل ألف الام واسم الفعل الأمر والمصدر

$$
2
$$

قسم الثان من الإنشاء الطلبي في سورة التحريم هوالنهي وهوفي قوله تعالى في

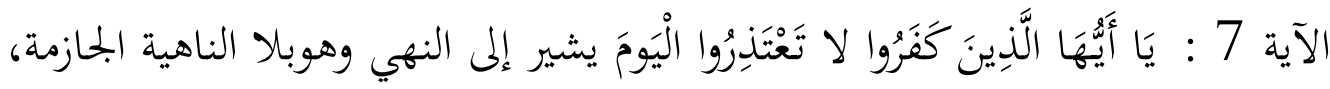
وذلك لإفادة "التيئيس". نظرت الباحثة إلى آية السابقة ودت أن كلمة : لا تعتذروا، تدل علي صيغة النهي لانه يستعمل أدة النهي. إذنفالنهي في سورة التحريم توجد كلمة واحدة في آية واحدة.

$$
3
$$

قسم الثالث من الإنشاء الطلبي في سورة التحريم هوالإستفهاموهويف قوله تعإلى في

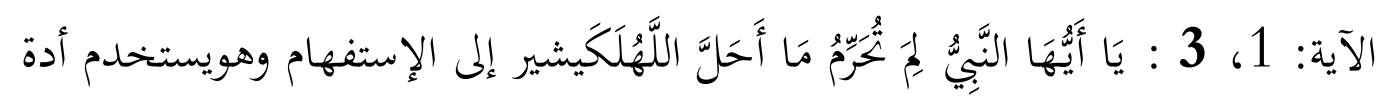
استفهام، واصله حرف الإستفهام فيه "ما" ولكن حذفت حرف الف اذا يدخل في اول حرف الاستفهام "ما" فيه ليفرق بين اسم الاستفهام وبغيره. لكن بشرط أن لا يوجد بعده اسم إشارة.

وقوله تعإلى : فَلَمَّا نَبَّأَهَا بِهِ قَالَتْ مَنْ أَنْبَأَكَ هَذَايشير إلى الإستفهام وهويستخدم أدة استفهام، وهويطلب بها تعيين أفراد العقلاء. وإذا نظرت الباحثة فيالأيتين السابقتينفوجدت أن كلمة : لم-من، تدل على الإستفهام لأهاتستعمل أدة الإستفهام. إذن فالإستفهام في سورة التحريم كلمتان في آيتين. 


\section{4}

قسم الرابع من الإنشاء الطلبي في سورة التحريم هو التمنوهوفي قوله تعإلى في الآية

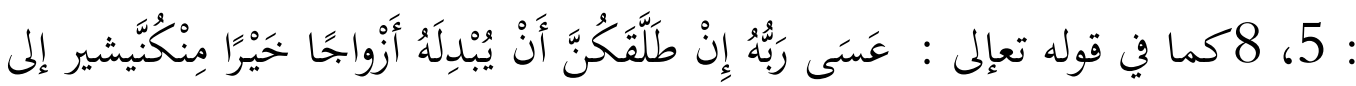

التمني لكن بمعنى الترجي، بيستخدام كلمة "عسى" وهي علامة التمنيفعل ماض جامد

من أفعال الرجاء، وكل لفظ "عسى" بمعنى الرجاء إذا وقعت من المخلوق، فإن كانت من

الخالق فهي للوقوع. وذكر أن معنى واجبة حتما، وعلل ذلك بأن الرجاء في حق الله

تعإلى غير وارد إذ إنالمتصرف المتدبر،والرجاء إنما يكون ممن لا يملك الشيء فيرجوه من رد بـ غيره. فمادام لفظ عسى ملتصقا بالخالق فمعناه تحقيق الوقوع،في هذه الآية لم تقع التبديل لعدم وقوع الطلاق.

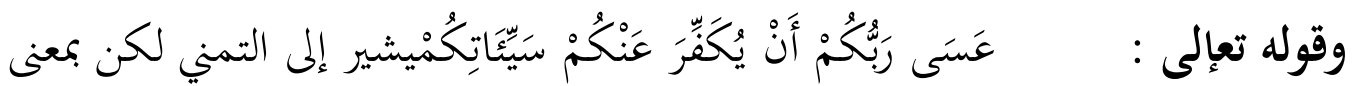
الترجي، بإستخدام كلمة "عسى" وهي علامة التمنيفعل ماض جامد من أفعال الرجاء.واذا نظرت الباحثة فيآيتين السابقتين فوجدتأن كلمة : عسى، تدل علمعنى التمني غير الحقيقي وهي ترجي لأهاتستعمل أدة الترجي. إذنفالتمني غير الحقيقي في سورة التحريم كلمتان في ايتين.

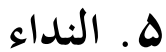

قسم الخامس من الإنشاء الطلبي في سورة التحريم هو النداء وهو في قوله تعإلى في

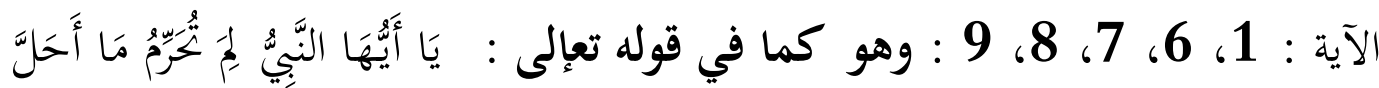
اللَّهُ لَكَّ. ويشير إلى النداء وهو باستخدام أداة النداء،فالنداء المعرف ب (أل) والإتيان بكلمة (أي) و(أية) كما وردت في الآية الكريمة فمعنى المنادى للحقيقي، فهذا هو معناه 
الأصلي. وقد قيل تخصيص النداء بلفظ "النبي" إنه يكون في أمر التشريع الخاص، أما النداء بلفظ الرسول فيكون في أمور التشريع العامة.

وقوله تعإلى : قُوا أَنْفُسَكُمْ وأَهْلِيكُمْم نَارًا . و ويشير إلى النداء وهو باستخدام أداة النداء،فالنداء المعرف ب (أل) والإتيان بكلمة (أي) و(أية) كما وردت في الآية الكريمة فمعنى المنادى للحقيقي، فهذا هومعناه الأصلي.

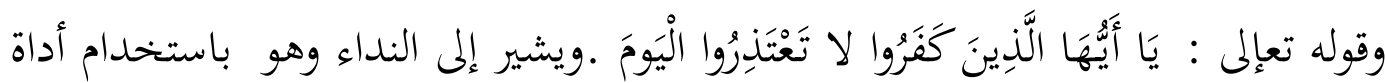
النداء، فالنداء المعرف ب (أل) والإتيان بكلمة (أي) و(أية) كما وردت في الآية الكريمة فمعنى المنادى للحقيقي، فهذا هومعناه الأصلي.

وقوله تعإلى: تُوبُوا إلى اللَّهِ تَوبَةَ نَصُوحًا ـو ويشير إلى النداء وهو باستخدام أداة النداء، فالنداء المعرف ب (أل) والإتيان بكلمة (أي) و(أية) كما وردت في الآية الكريمة فمعنى المنادى للحقيقي، فهذا هومعناه الأصلي.

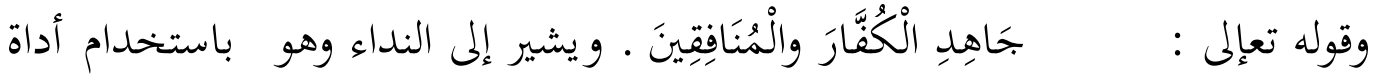
النداء،فالنداء المعرف ب (أل) والإتيان بكلمة (أي) و(أية) كما وردت في الآية الكريمة فمعنى المنادى للحقيقي، فهذا هو معناه الأصلي. وقد قيل تخصيص النداء بلفظ "النبي" إنه يكون في أمر التشريع الخاص، أما النداء بلفظ الرسول فيكون في أمور التشريع العامة. وإذا نظرت الباحثة إلى الآيات السابقاتأن كلمة : يا،تدل على النداء لأغا تستعمل بأدة النداء. إذن فالنداء في سورة التحريم خمس كلمات في خمس ايات. معاني الإنشاء الطلبي الموجودة في سورة التحريم 


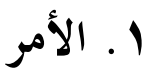

الأمر الموجودة في سورة التحريم عشرة ولها معنان مختلفة وهي :

\begin{tabular}{|c|c|c|c|}
\hline البيانات & الجملة والأية & المعنى & الرقم \\
\hline فلب الحقيغة الأمر في هذه الآية بمعنى النصح لأن هذا الأمر & 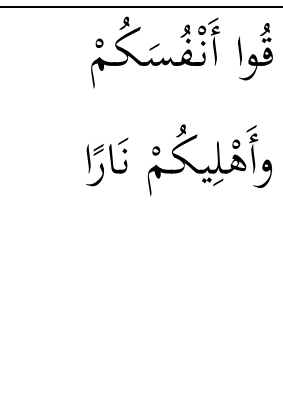 & النصح & .1 \\
\hline 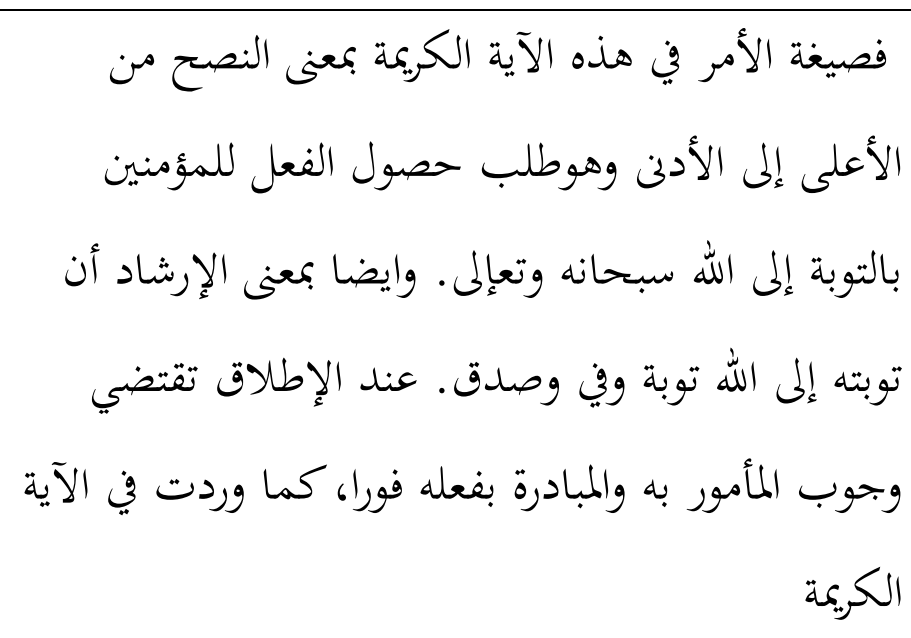 & 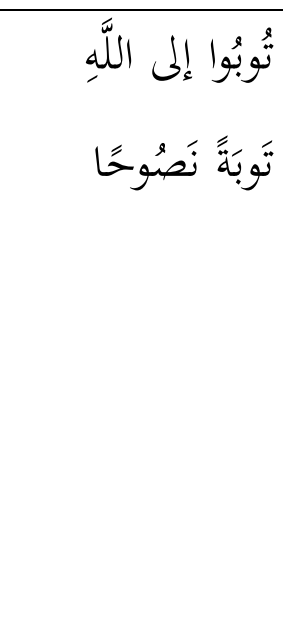 & والإرشاد &.$Y$ \\
\hline فأل ألصيغة الأمر في هذه الآية تدل على معنالدعاء،لأن هذا & رَبَََنَا أَتْتِمْمْ لَنَا نُورَنَا & الدعاء & $r$ \\
\hline
\end{tabular}




\begin{tabular}{|c|c|c|c|}
\hline 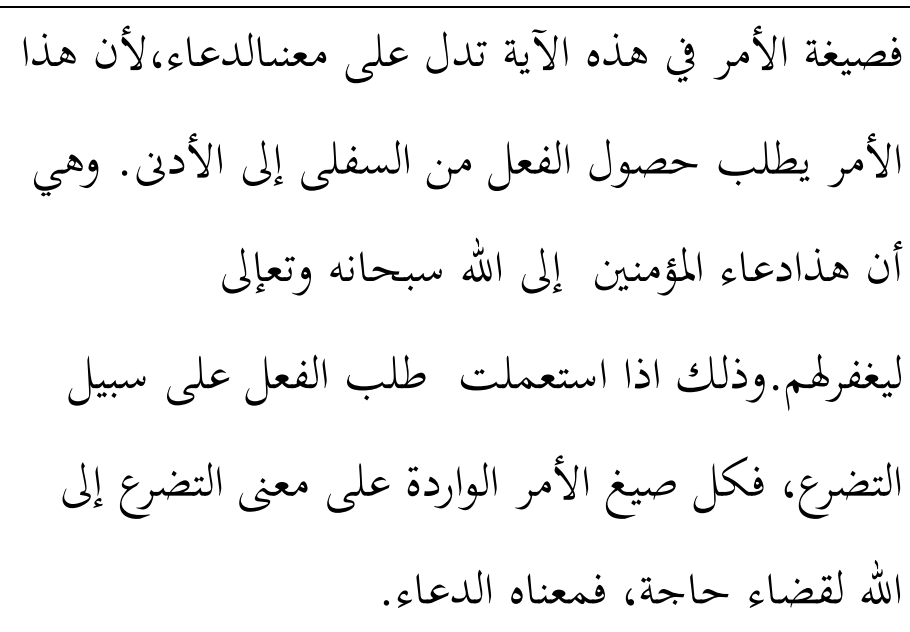 & واغْفِرْ لَنَا & الدعاء & $\varepsilon$ \\
\hline 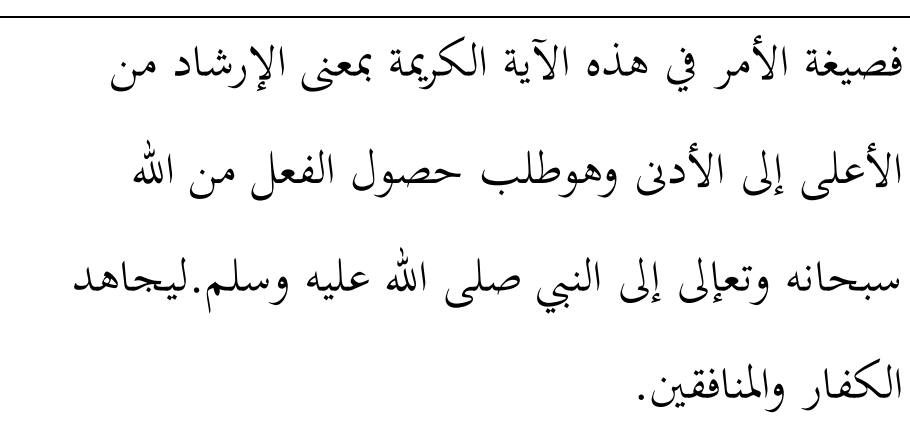 & 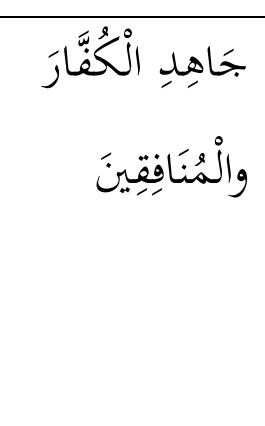 & الإرشاد & .0 \\
\hline فيعة الأمر في هذه الآية الكريمة بمعنى التأديب من & واغْلُظْ عَلَيْهِهْْْ & التأديب & .7 \\
\hline 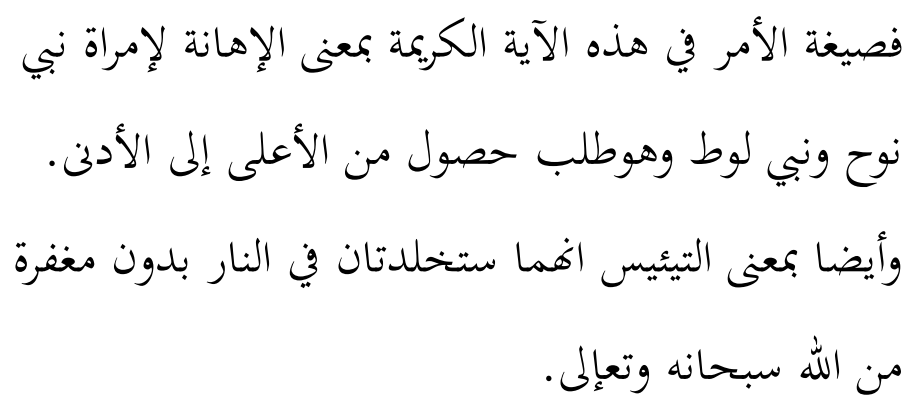 & 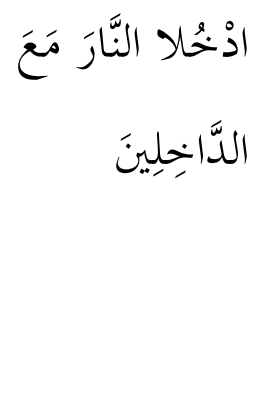 & والإهانة &.$V$ \\
\hline فصيغة الأمر في هذه الآية تدل على معنـالدعاء،لأن هذا & رَبِِّ ابْنِ رلي & الدعاء &.$\wedge$ \\
\hline
\end{tabular}




\begin{tabular}{|c|c|c|c|}
\hline والأمر يطلب حصول الفعل من السفلى إلى الأدنى. وهي & 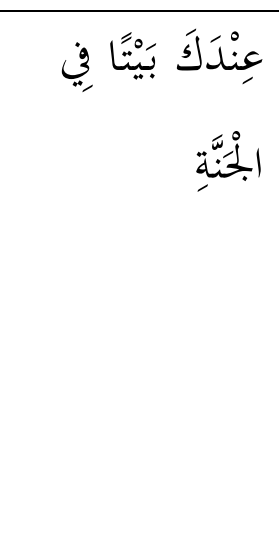 & & \\
\hline فالعيغة الأمر في هذه الآية تدل على معنسالدعاء،لأن هذا & 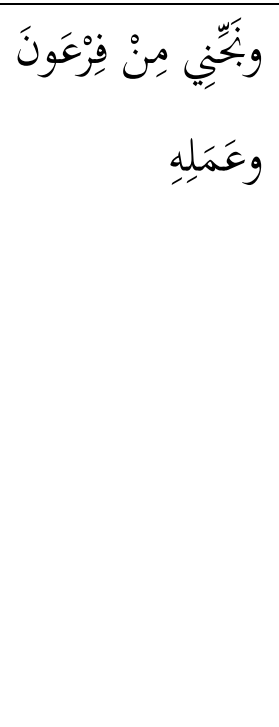 & الدعاء & .9 \\
\hline فالأمر يطلب الأمر في هذه الآية تدل على معنـالدعاء،لأن هذا & 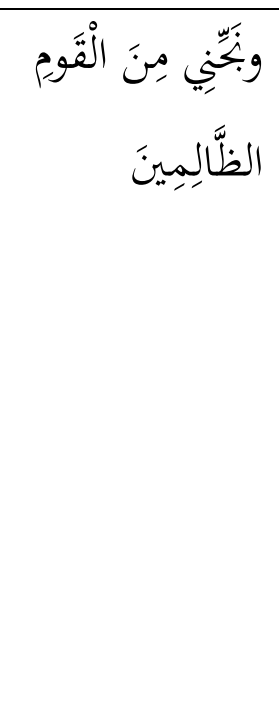 & الدعاء & .1. \\
\hline
\end{tabular}


النهي في سورة التحريم واحدوأما معناه هو:

\begin{tabular}{|c|c|c|c|}
\hline البيانات & الجملة والأية & | المعنى | & الرقم \\
\hline 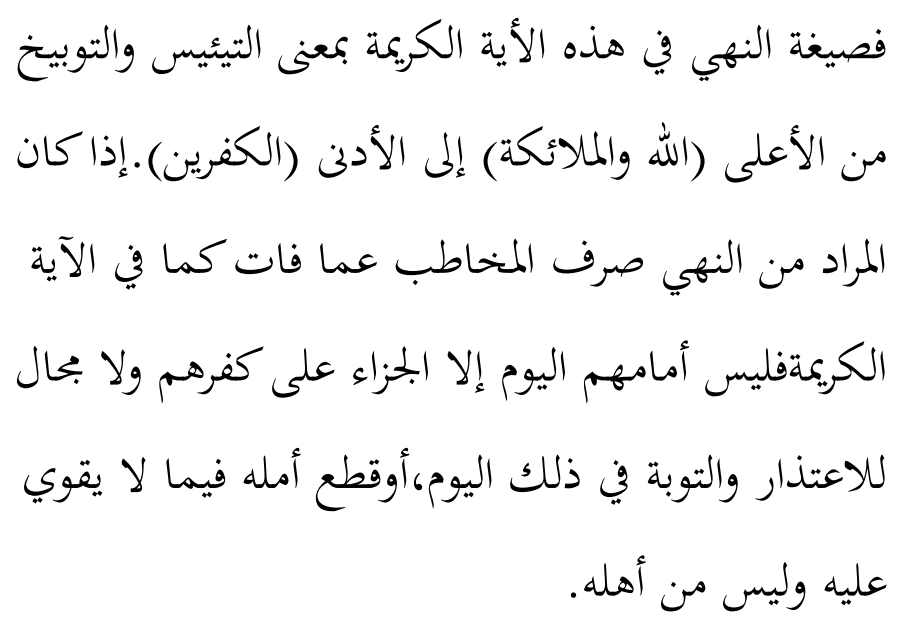 & 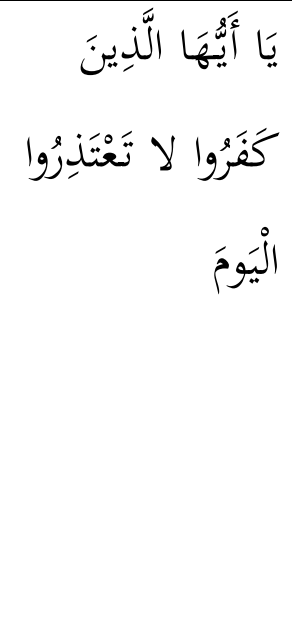 & |التيئيس & .1 \\
\hline
\end{tabular}

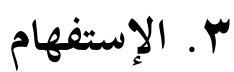

الإستفهام في سورة التحريم إثنان وهما:

\begin{tabular}{|c|c|c|c|}
\hline البيانات & الجملة & المعنى & الرقم \\
\hline فصبيغة الإستفهام في هذه الأية بمعنى الإنكار من الله & 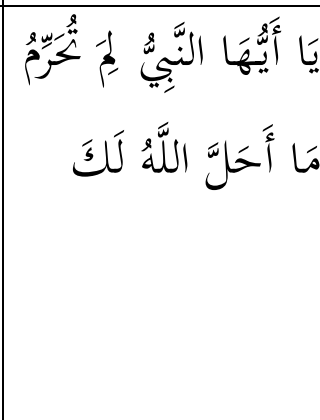 & الإنكار & .1 \\
\hline
\end{tabular}




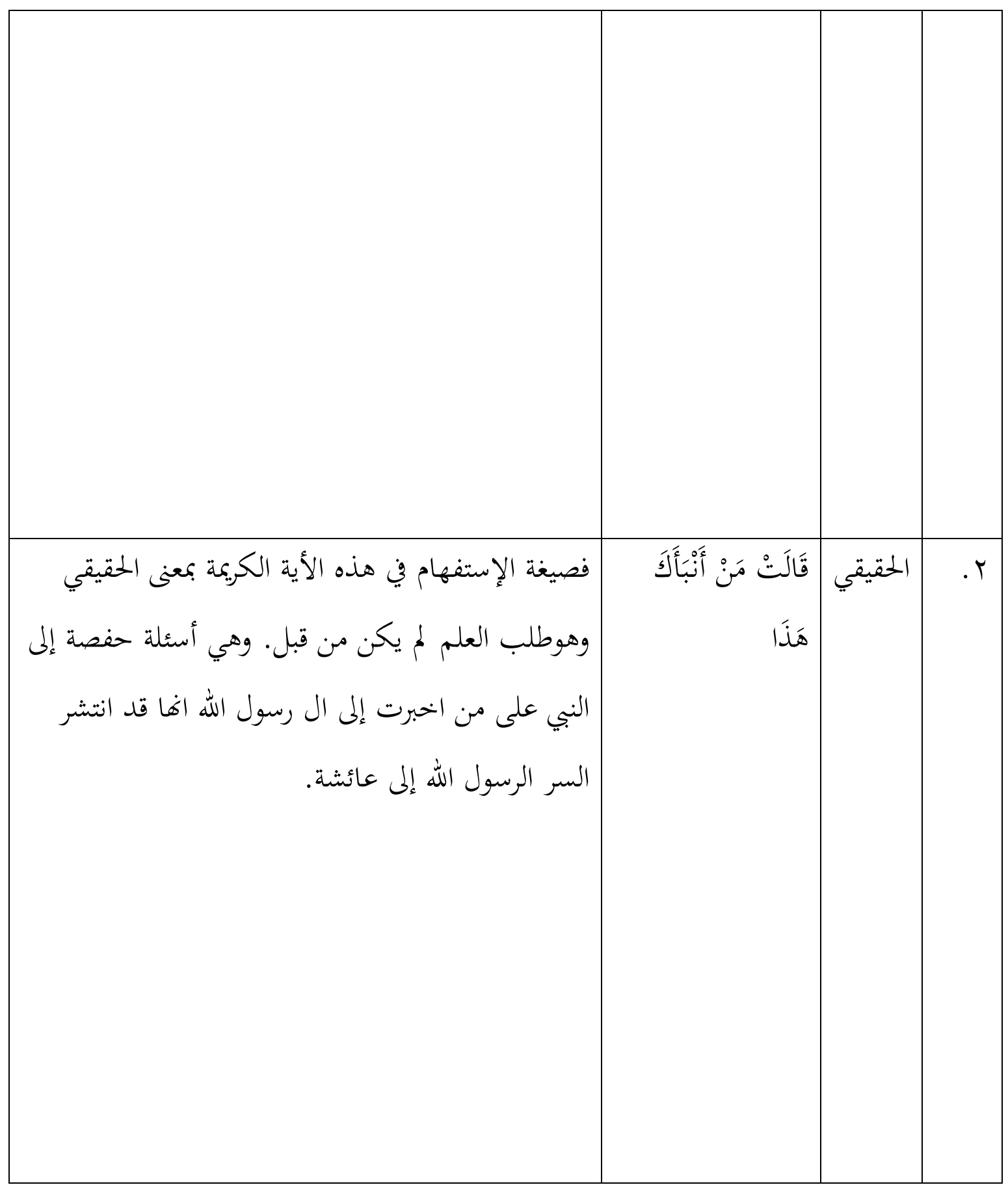

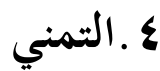


التمني في سورة التحريم إثنان، وهوالتمني بمعنى غير حقيقي ولا يوجد فيها معنى الحقيقي، وهوفيما يلي :

\begin{tabular}{|c|c|c|c|}
\hline البيانات & الجملة والأية & المعنى & الرقم \\
\hline 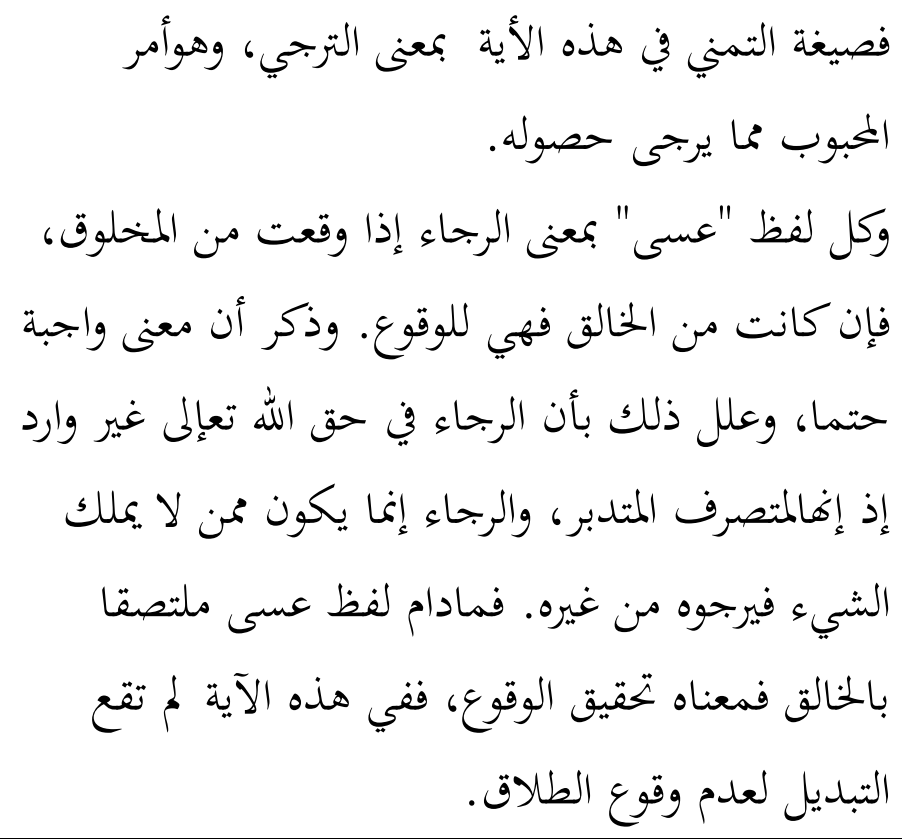 & 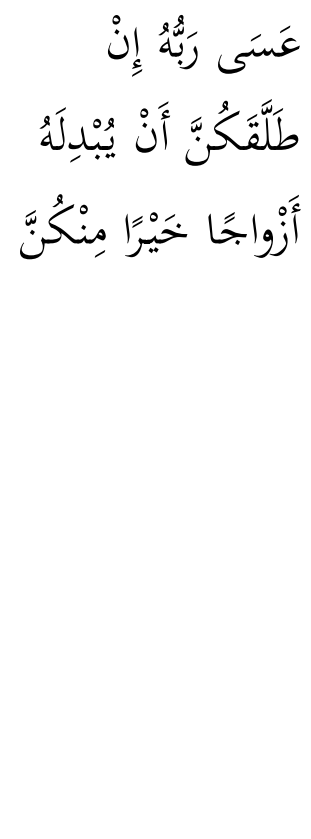 & للتحقيق & .1 \\
\hline 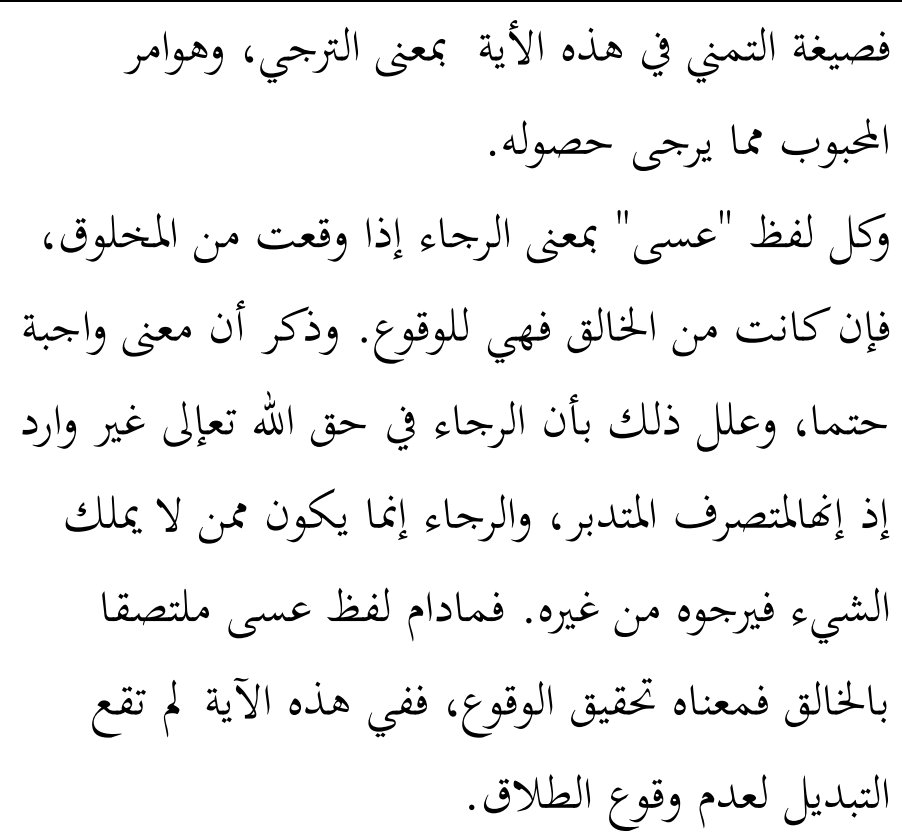 & 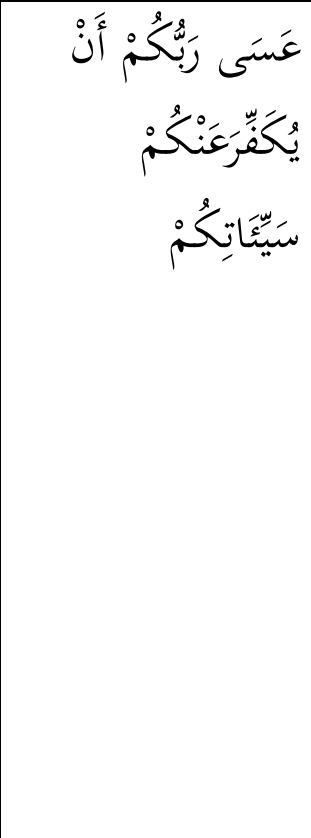 & الترجي &.$Y$ \\
\hline
\end{tabular}


النداء في سورة التحريم خمسة،معنى مختلفة كما يلي :

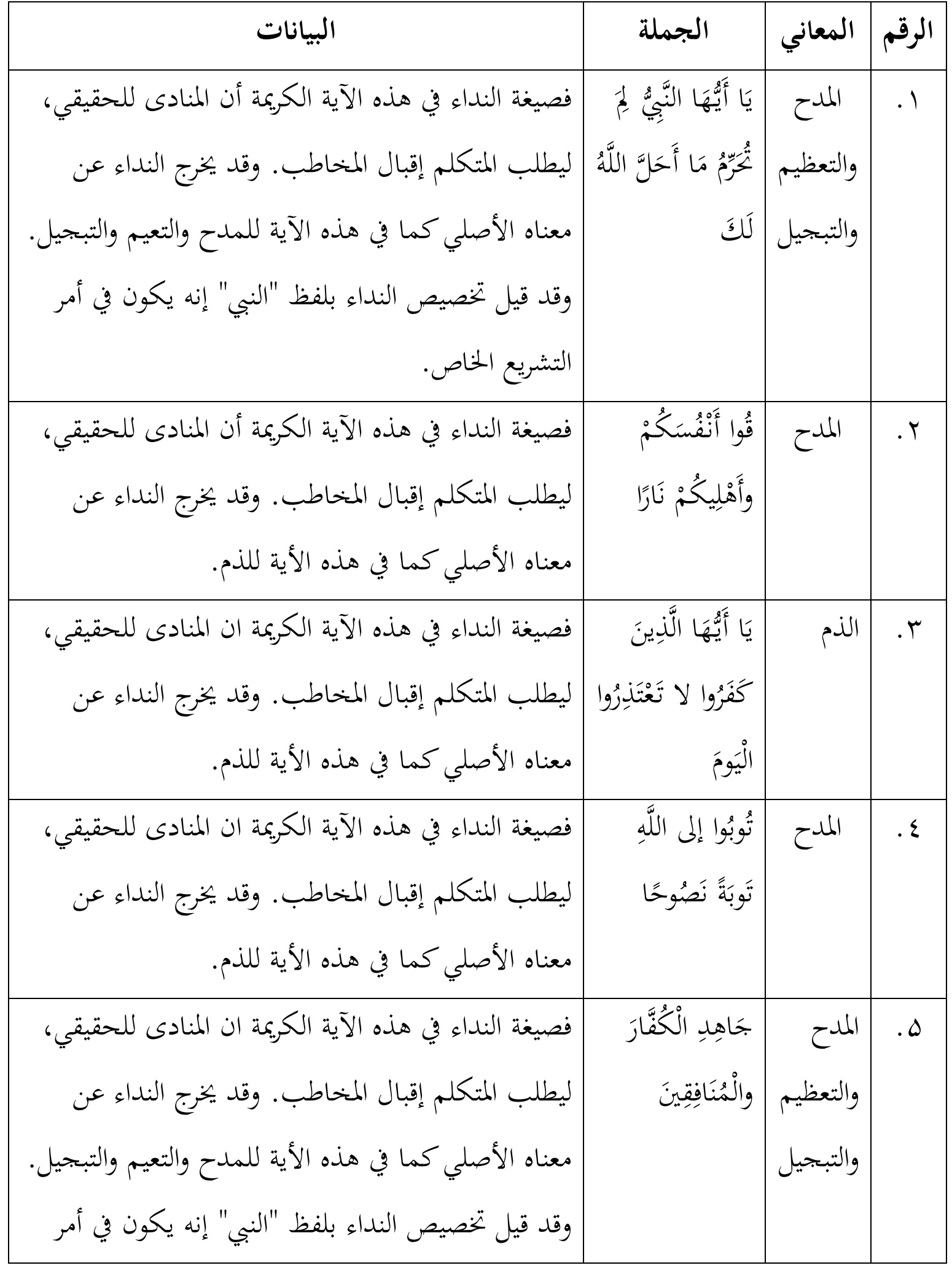




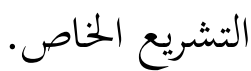

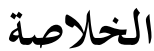

بعد ما بحثت الباحثة في هذا البحث العلمي، استنتجت الباحثة فيما يلي :

ا ـ كان الإنشاء الطلبي في سورة التحريم يتكون . ب كلمة، تسع كلمات لأمر، كلمة للنهي، كلمتين لإستفهام، كلمتين للتمني، وخمس كلمات للنداء.

O . وأما معاني الإنشاء الطلبي في سورة التحريم هناك معنى الحقيقي وغير

الحقيقي. وجميع معاني الأمر بغير حقيقي هي:النصح-الإرشاد-الدعاء-التأديب-

الإهانة. ومعان النهي ايضا بغير حقيقي هي : التيئيس والتوبيخ.معناني الإستفهام

هناك الحقيقي وهي : (قالت من أنبأك هذا) وهناك معنى غير حقيقي

هي:الإنكار . ومعاني التمني وهي معنى الترجي. ومعاني النداء كله معنى بغير

$$
\text { الحقيقي هي : المدح والذم. }
$$

\section{المراجع}

أبي الفضل شهاب الدين السيد المحود الألوسي البغدادي، روح المعاني في تضسير القرآن العظيم والسبع المثاني، (بيروت- لبنان: دار اللفكر)

أحمد الهاثمي، جواهر البلاغة في المعاني واليبان والبليع ، (بيروت لبنان: دار

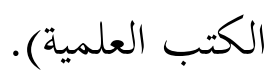




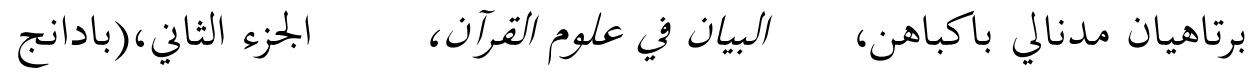

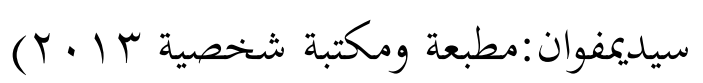

جلال الدين السيوطي،شرح عقود الجمان في المعاني والبيان ، -(بيروت ، لبنان :

$$
\text { دار الكتب العلمية ، 11 (ب) }
$$

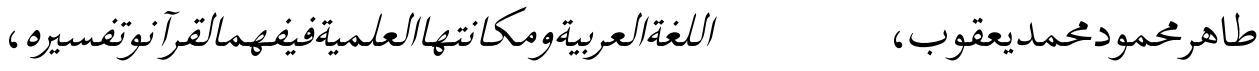

$$
\text { (باكستان: بحلة قسم العربي، } 1 \text { ( • ب م) }
$$

محمودأحمدالزين، اهمية لغة العربية في فهم القرآن والسنة ، (دبي: دائرة شؤون

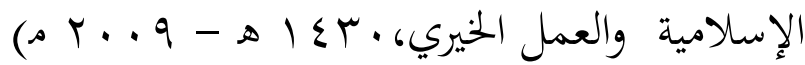

$$
\begin{aligned}
& \text { درامات في علوم القرآن،) }
\end{aligned}
$$

الدكتور محمد ابو بكر إسماعيل ، درامات في علوم القرآن، ( القاهرة:دار

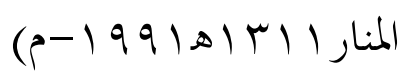

السيد أحمد الماشمي ، جواهر البلاغة ، (إندونيسيا: مكتبة دار احياء الكتب

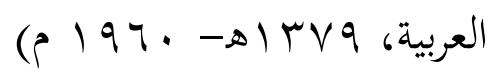

عبد العزيز عتيق، علم المعاني الطبعة الأولى، (بيروت لبنان : دار النهضة العربية،

$$
(\zeta \cdot \cdot q / \Delta) \leqslant r \cdot 6
$$

عبد الله بن صالح الفراج، أطروحة ،بلاغة أساليب الإنشاء في سورة الحجر،

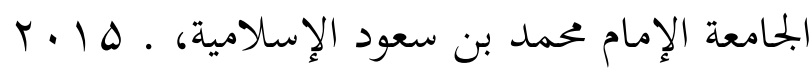

العبد المرحوم أحمد الماشمي، جواهر البلاغة في المعاني والبيان والبديع، (اندونيسيا:

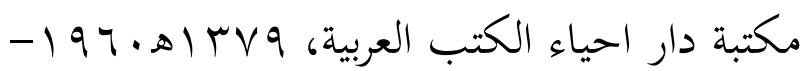

$$
\begin{aligned}
& \text { علوم البلاغة البديع-البيان-المعاني، ص. برمب }
\end{aligned}
$$

علي الجارم ومصطفى آمين، البلاغة الواضحة المعاني والبيان والبليع ، (دار

$$
\text { (المعارف) }
$$




$$
\begin{aligned}
& \text { محمد أحمد قاسم ومحي الدين ديب، علوم البلاغة البليع البيان المعاني، (طرابل- }
\end{aligned}
$$

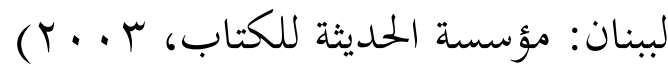

$$
\begin{aligned}
& \text { حمدل احمد قاسم، محي الدين ديب، علوم البلاغةالبديع-البيان-المعاني الطبعة } \\
& \text { الأولى ،(طرابلس - لبنان: المؤسسة الحديثة للكاتب؟ . . . r )، } \\
& \text { محمد بن محمد أبو شهبة، الملدخل للدراسة القربن الكميم ، (القاهرة: مكتبة السنة }
\end{aligned}
$$

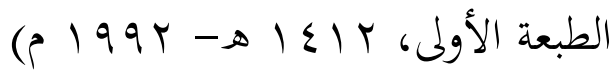

$$
\begin{aligned}
& \text { محمد سا لم محيسن، تاريخ القرآن الكيمي، (إسكندرية: مؤسسة شباب الجامعة) } \\
& \text { مصطفى الغلايين، جاميع الدروس العربية ، (القاهرة: دار السلام، الطبعة الرابعة } \\
& \left.\cdot \int(r+1)-8\right) \leqslant r q \\
& \text { مناع القطان، في علوم القرآن، (الرياض: مكتبة المعارف، م · ع اهـ191 |- م) } \\
& \text { نور أزهاري جميل، البحث، من معناني الإنشاء الطلبي في سورة المائدة (دراسة }
\end{aligned}
$$

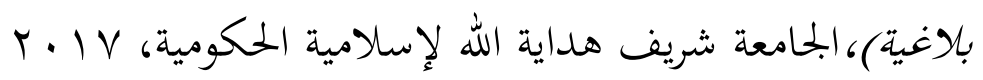

Akhmad Sya'bi, Kamus Al-Qalam, (Sumenab :Halim Surabaya, Sa'ban 1418 H-Desember 1997 M)

Departemen Agama Republik Indonesia, AL-Quran dan Terjemahnya, (Surabaya: C.V. Jaya Sakti, 1045 h- 1984 m)

M. Zaim, Methode Penelitian Bahasa Pendekatan Struktural,(Padang: FBS UNP Press Padang, 2014)

M.Qurais Shihab, Tafsir al-Misbah,(Jaka rta: lentera hati,2002)

Sugiyono, Metode Penelitian Pendidikan; Pendekatan Kuantitatif, Kualitatif dan $R \& D$ (Bandung: ALFABETA, 2010)

Sugiyono, Metode Penelitian Pendidikan; Pendekatan Kuantitatif, Kualitatif dan $R \& D$ 